\title{
Erratum zu: Subjektive Sicherheit zur Steigerung der Akzeptanz des automatisierten und vernetzten Fahrens
}

\author{
Uwe Drewitz $^{1}$ (D) Marc Wilbrink ${ }^{1} \cdot$ Michael Oehl $^{1}$ (D) $\cdot$ Meike Jipp ${ }^{1} \cdot$ Klas Ihme $^{1}$
}

Online publiziert: 2. August 2021

(c) Der/die Autor(en) 2021

\section{Erratum zu:}

\section{Forsch Ingenieurwes 2021}

https://doi.org/10.1007/s10010-021-00500-y

In der Originalveröffentlichung des Artikels wurde der Name des Autors Michael Oehl leider falsch geschrieben.

Der Beitrag wurde korrigiert.

The original version of this paper was inadvertently published with an incorrect author name for the author Michael Oehl.

The original article has been corrected.

Funding Open Access funding enabled and organized by Projekt DEAL.

Open Access Dieser Artikel wird unter der Creative Commons Namensnennung 4.0 International Lizenz veröffentlicht, welche die Nutzung, Vervielfältigung, Bearbeitung, Verbreitung und Wiedergabe in jeglichem Medium und Format erlaubt, sofern Sie den/die ursprünglichen Autor(en) und die Quelle ordnungsgemäß nennen, einen Link zur Creative Commons Lizenz beifügen und angeben, ob Änderungen vorgenommen wurden.

Die in diesem Artikel enthaltenen Bilder und sonstiges Drittmaterial unterliegen ebenfalls der genannten Creative Commons Lizenz, sofern sich aus der Abbildungslegende nichts anderes ergibt. Sofern das betreffende Material nicht unter der genannten Creative Commons Lizenz steht und die betreffende Handlung nicht nach gesetzlichen Vorschriften erlaubt ist, ist für die oben aufgeführten Weiterverwendungen des Materials die Einwilligung des jeweiligen Rechteinhabers einzuholen.

Weitere Details zur Lizenz entnehmen Sie bitte der Lizenzinformation auf http://creativecommons.org/licenses/by/4.0/deed.de.

Die Online-Version des Originalartikels ist unter https://doi.org/ 10.1007/s10010-021-00500-y zu finden.

Uwe Drewitz

uwe.drewitz@dlr.de

1 Institut für Verkehrssystemtechnik, Deutsches

Zentrum für Luft- und Raumfahrt e. V. (DLR),

Lilienthalplatz 7, 38108 Braunschweig, Deutschland 